\title{
CONTABILIDADE E SUSTENTABILIDADE: UMA ANÁLISE DOS ARTIGOS PUBLICADOS EM PERIÓDICOS QUALIS NO PERÍODO DE 2007 A 2011
}

\author{
ACCOUNTING AND SUSTAINABILITY: AN ANALYSIS OF ARTICLES PUBLISHED \\ IN JOURNAL QUALIS THE PERIOD 2007 TO 2011
}

\author{
Luciano Gomes dos Reis \\ lucianoreis@uel.br \\ Universidade Estadual de Londrina
}

\author{
Marcelo Resquetti Tarifa \\ marcelotarifa@hotmail.com \\ Universidade Estadual de Londrina
}

\begin{abstract}
Resumo
O objetivo do presente estudo foi verificar junto aos periódicos nacionais da área contábil referenciadas pelo QUALIS-CAPES as publicações relativas à área de sustentabilidade ambiental no período de 2007 a 2011 sob a ótica bibliométrica. Como objetivo secundário, observou-se se a crise mundial de 2008 influenciou negativamente a quantidade de produção na temática de sustentabilidade ambiental. Na metodologia aplicada à pesquisa, a caracterização voltou-se a um estudo descritivo com a utilização de pesquisa bibliográfica, bem como abordagem quali-quanti em relação à problemática principal. De acordo com a investigação, concluiu-se que em apenas 5,26\% dos 1179 artigos analisados a temática de sustentabilidade ambiental é abordada, sendo que os estudos mais explorados tratam da evidenciação/evidenciação ambiental e contabilidade ambiental. Pôde-se verificar também que a crise financeira mundial de 2008 não provocou impacto negativo nas produções sobre o tema, tendo em vista o ápice das publicações ter ocorrido no ano de 2010. No campo bibliométrico, os 62 artigos apresentaram predominância metodológica de estudos qualitativos quanto ao método, documentais quanto à estratégia, análises documentais quanto à técnica e, por fim, descritivos e exploratórios quanto ao tipo de pesquisa.
\end{abstract}

Palavras-chave: Contabilidade; Sustentabilidade Ambiental; Periódicos Científicos; Bibliometria

\begin{abstract}
The aim of this study was to verify with regular national accounting area referenced by CAPES-QUALIS publications relating to the area of environmental sustainability in the period from 2007 to 2011 under the bibliometric perspective. As a secondary objective, it was observed that the global crisis of 2008 negatively affected the amount of production on the theme of environmental sustainability. In the methodology applied to the research, the characterization turned a descriptive study with the use of literature as well as qualitative and quantitative approach in relation to the problematic page. According to research, it was concluded that in 1179 only $5.26 \%$ of the articles examined the issue of environmental sustainability is addressed, and the most exploited studies dealing with the disclosure / environmental disclosure and environmental accounting. It might also be noted that the global financial crisis of 2008 caused no negative impact on productions on the subject, in view of the apex of the publications have occurred in 2010. In bibliometric field, the 62 articles were predominant methodology of qualitative studies regarding the methods, documentary about the strategy, analyzes documentary about the technique and finally, exploratory and descriptive about the type of research.
\end{abstract}


Keywords: Accounting, Sustainability, Scientific Journals; Bibliometrics

Artigo recebido em: 14/07/2013; Aceito em: 13/11/2014

\section{INTRODUÇÃO}

Nos últimos anos, as questões ligadas à sustentabilidade apresentam-se como um tema contemporâneo, despertando o interesse de pesquisadores em diversas áreas, da química e biologia à economia. $\mathrm{O}$ tema está presente nas diretrizes de governos, sendo uma atividade fim para diversas organizações não-governamentais, que atuam em áreas da sustentabilidade, podendo provocar impacto direto em diversas atividades empresariais. Inicialmente, as preocupações relativas à área ambiental e social representavam apenas o de incrementar os objetivos financeiros dos acionistas (FRIEDMAN, 1970). Os novos modelos de gestão, dessa forma, devem levar em consideração o aspecto multidimensional da sustentabilidade, indo além dos aspectos econômicos, sendo direcionados para incluir diferentes pontos de vista dos interessados na organização (RODRIGUES, DUARTE, 2011). Nesse processo de gestão, são essenciais informações que possam conduzir os tomadores de decisão para a melhor forma possível durante o seu processo decisório, seja internamente, seja externamente à organização.

A Ciência Contábil é um dos instrumentos necessários para promover aos gestores essas informações, permitindo o conhecimento dos eventuais passivos ambientais, que podem promover impacto nos custos, bem como permite a avaliação da possibilidade de existência de determinados ativos ambientais, que possam gerar benefícios econômicos para a empresa. Como um dos ramos de estudos da Ciência Contábil, a denominada Contabilidade Ambiental permite a realização de estudos e pesquisas, utilizando-se das técnicas e do arcabouço teórico da Ciência Contábil, podendo gerar conhecimento e trazendo à tona diferentes aspectos da gestão, que tenham por escopo a vertente da sustentabilidade.

Por outro lado, o interesse dos gestores das organizações e dos governos a respeito da questão ambiental tem sofrido efeitos positivos e negativos, provenientes da crise financeira, que teve início em 2008. De acordo com Dowbor (2008), a crise financeira mundial de 2008 teve um efeito sistêmico, abrindo espaço para que a sociedade com um todo possa resolver dois grandes desafios: a desigualdade e a questão ambiental. Entretanto, de acordo com Barbosa (2011) estudos realizados pela Ernst \& Young em 2011 demonstram que a instabilidade na região do Euro pode elevar para US\$ 45 bilhões o déficit no financiamento de ações climáticas até 2015, como um dos reflexos dos efeitos da crise iniciada em 2008.

Em virtude da redução do interesse das organizações e dos governos por questões ligadas à sustentabilidade, bem como pelo surgimento de outras temáticas como crises financeiras em determinados mercados e mudanças na normatização contábil, pode haver a tendência de alteração no interesse de pesquisadores para assuntos que apresentem maior receptividade e disponibilidade de informações para a realização de estudos. O trabalho de Pessan et al (2012), ao analisar os artigos sobre contabilidade ambiental publicados no Congresso USP de Controladoria e Contabilidade demonstrou que o maior número de artigos publicados ocorreu no ano de 2006, sendo que nos anos seguintes apresentou-se uma queda e posterior estabilização dos artigos apresentados sobre essa temática. Rosa et al (2011) também constataram queda na produção

R. Cont. Ufba, Salvador-Ba, v. 8, n. 3, p. 21 - 37, set-dez 2014 
cientifica sobre o tema contabilidade ambiental na Espanha, nos anos de 2007 e 2008, reduzindo de 10 artigos em 2006 para 6 artigos em 2007 e 2008. Quando abordado sob a ótica das publicações em livros, o trabalho de Reis et al (2011) apresentou que, de um total de 13 livros publicados, 12 tiveram sua publicação até o ano de 2008, sendo que foi publicado apenas um livro em 2010. Considerando-se que, na área contábil, a principal temática abordada sob a ótica da sustentabilidade é a Contabilidade Ambiental, e suas contribuições para o processo de tomada de decisão, verifica-se que não há um padrão a respeito do interesse de pesquisadores sobre o tema.

Tendo em vista o contexto exposto até o presente momento, apresentou-se o seguinte problema de pesquisa: qual o perfil das publicações sobre a temática da sustentabilidade ambiental, em periódicos científicos de Ciências Contábeis, no período de 2007 a 2011 ? Com base nessa questão de pesquisa, o objetivo do presente artigo foi verificar, junto aos periódicos da área contábil referenciados pelo QUALIS-CAPES, as características das publicações relativas à área de sustentabilidade ambiental no período de 2007 a 2011. De forma complementar, buscou-se analisar se ocorreram alterações no nível de publicações sobre a temática da sustentabilidade ambiental na área contábil, antes e após a crise financeira de 2008.

O presente artigo está dividido em quatro seções: esta introdução, onde é realizada a contextualização e apresentado do problema e do objetivo da pesquisa. A segunda seção é destinada à revisão da literatura sobre o tema. Na terceira seção é apresentada a metodologia de pesquisa. Os dados apurados e a análise e discussão dos resultados são apresentados na quarta seção. Na última seção são apresentadas as conclusões do artigo.

\section{REFERENCIAL TEÓRICO}

\subsection{A contabilidade e sua função social}

A Ciência Contábil, desde o seu início, esteve inserida em um contexto no qual realiza estudos e se relaciona com o patrimônio das entidades de uma forma inequívoca. $\mathrm{O}$ patrimônio, seja ele individual ou coletivo, organizado sob a forma de empresas ou instituições, está contido em um aspecto amplo, que envolve questões de natureza econômica e tem impacto na sociedade como um todo.

A classificação da contabilidade como Ciência Social Aplicada não ocorreu por acaso, uma vez que, diferentemente das ciências exatas, ela sofre os efeitos das mudanças que afetam a sociedade, permitindo-se alterações seja por atos provenientes da legislação, seja pelo surgimento de novos fatos, antes inexplorados pela teoria contábil.

Ao prover os seus usuários com uma gama de informações de naturezas distintas, a Contabilidade permite uma série de posicionamentos a respeito de determinados temas, seja de forma direta, seja de forma indireta. Para Campos (2011) conceitos como responsabilidade e transparência estão presentes na origem da própria contabilidade, sendo relevantes para a eficácia no processo de comunicação entre a empresa e os usuários da informação contábil por ela gerada. A necessidade de transparência e a responsabilidade, assumidas perante a sociedade, fazem com que a contabilidade assuma uma função social de elevado grau, uma vez que por intermédio da informação contábil pode ocorrer o exercício e a delegação de poder (MENDONÇA NETO, et al, 2010).

Considerando-se o poder contido nos relatórios de natureza contábil e a importância social da Contabilidade, a partir da década de 1960 foram criadas demonstrações que permitissem uma visualização da função social das organizações, por intermédio de um

R. Cont. Ufba, Salvador-Ba, v. 8, n. 3, p. 21 - 37, set-dez 2014 
relatório de natureza contábil, que pudesse evidenciar informações de natureza social. Uma dessas demonstrações que surgiram foi o Balanço Social, que teve sua divulgação por parte das empresas obrigatória na França a partir do ano de 1977 (Santos, 2007) . Essa demonstração teve seu surgimento considerando uma situação, na qual havia uma crescente cobrança por parte da sociedade, de uma maior responsabilidade social das empresas, que teve seu início nos movimentos sociais na década de 60 daquele século, de acordo com Santos (2007).

No Brasil, surgiram modelos de divulgação do Balanço Social, como o modelo IBASE e o modelo preconizado pelo Instituto Ethos, a partir dos anos 1980. Esses modelos eram estruturados de forma semelhante, trazendo informações de natureza social, ambiental e do corpo funcional. Contudo, em virtude de diversos fatores, as empresas acabaram por não prosperar na sua divulgação, uma vez que não havia obrigatoriedade legal. A esse respeito, Ribeiro, Van Bellen e Carvalho (2011) concluíram em sua pesquisa que o disclosure ambiental das companhias, uma das formas de se divulgar informações de natureza social, reage aos estímulos regulatórios de seus países, ou seja, as empresas só realizam a divulgação se ela for regulamentada.

Atualmente, o relatório de sustentabilidade que está sendo adotado por algumas empresas é o modelo do GRI - Global Reporting Initiative. O GRI é uma organização não governamental internacional com sede em Amsterdã, na Holanda, cuja missão é desenvolver e disseminar globalmente diretrizes para a elaboração de relatórios de sustentabilidade utilizados voluntariamente por empresas de todo o mundo que desejam dar informação sobre os aspectos econômicos, ambientais e sociais de suas atividade, produtos e serviços (GRI, 2013).

Por meio de divulgações de natureza socioambiental, das quais muitas informações são extraídas de relatórios de natureza contábil-financeira, a sociedade passa a dispor de um maior nível de disclosure, permitindo uma visão mais ampla dos impactos e benefícios provocados pela organização. A próxima seção destaca, em especial, a contribuição da contabilidade, a respeito da divulgação de informações que sejam úteis para a área de sustentabilidade.

\subsection{A sustentabilidade na área de contabilidade}

As preocupações sobre assuntos relativos à sustentabilidade, na atualidade, transformaram-se em uma questão consensual, visando a criação de um novo modo de desenvolvimento, permitindo-se que haja uma combinação entre eficiência da área econômica, sem, no entanto, se esquecer das áreas social e ambiental. A combinação desses elementos somente será possível se houver um esforço conjunto de todos com objetivo de atingir o bem-estar geral no futuro (KRAEMER, 2006).

Segundo Pfitcher (2004), à medida que há uma melhor conscientização da valorização do meio ambiente, surge uma necessidade de se conciliar o desenvolvimento econômico com a preservação ambiental. A partir desse momento, quando as questões ligadas à sustentabilidade se entrelaçam com questões de ordem econômico-financeiras, é que a Contabilidade Ambiental passa a ter uma função primordial no quotidiano empresarial, uma vez que irá ser responsável por apurar, mensurar, registrar e, principalmente, divulgar os impactos das atividades organizacionais no meio-ambiente.

Na visão de Tinoco e Kraemer (2008, p.153) a Contabilidade Ambiental é conceituada como:

..."o veículo adequado para divulgar informações sobre o meio ambiente. Esse é um fator de risco e de competitividade de primeira ordem. A não-inclusão dos custos,

R. Cont. Ufba, Salvador-Ba, v. 8, n. 3, p. 21 - 37, set-dez 2014 
despesas e obrigações ambientais distorcerá tanto a situação patrimonial como a situação financeira e os resultados da empresa".

Em uma visão mais ampla, também utiliza-se o termo "contabilidade social e ambiental”, que na definição de Gray; Owen e Maunders apud Mathews (1997, p. 483):

\footnotetext{
É o processo de comunicação dos efeitos sociais e ambientais das organizações, ações econômicas de interesse particular de grupos dentro da sociedade e para a sociedade em geral. $\mathrm{O}$ tema envolve estender a prestação de contas das companhias para além de regras tradicionais, ou seja, da contabilidade financeira. Tal processo parte da hipótese de que as companhias têm maiores responsabilidades dentro da sociedade, que vão além de "fazer" dinheiro para seus acionistas.
}

Verifica-se, em ambos os conceitos, a necessidade de prestação de contas de forma abrangente e transparente, indo além dos parâmetros tradicionais da área contábil. Os maiores interessados nas informações contábeis ultrapassam os portões das organizações, sendo que, além do lucro e da geração de caixa, também devem estar inseridas questões relativas à área social e ambiental. A possibilidade de não inclusão dessas informações pode, inclusive, gerar impactos futuros, como no caso da empresa britânica BP Petroleum, que conforme as informações provenientes das demonstrações contábeis teve que realizar um provisionamento de US\$37,2 bilhões, em virtude do acidente ocorrido em Abril de 2010, no Golfo do México. A existência de um risco ambiental potencial deve ser objeto de relato, especialmente para as atividades consideradas potencialmente poluidoras e cuja probabilidade de danos ambientais seja provável.

Para Kraemer (2006), os contadores têm um papel fundamental nesta perspectiva, uma vez que depende desses profissionais elaborar um modelo adequado para esta entidade, incentivando as empresas a adotarem ações que levem à gestão ambiental de forma consciente, gerando dados e informações apresentáveis contabilmente, seja por intermédio dos relatórios de sustentabilidade, seja por intermédio das próprias demonstrações financeiras tradicionais. Corroborando com essa visão, Ballou et al (2012) afirmam que o aumento da participação dos contadores nas questões ligadas à sustentabilidade pode proporcionar benefícios significativos para as organizações e seus stakeholders, mas o envolvimento de profissionais contábeis com essas questões ainda é raro, de acordo com um levantamento realizado com 178 responsáveis por questões de responsabilidade corporativa,

Na visão de Callado e Callado (2007), a contabilidade ambiental deve servir como instrumento útil para as organizações, sendo necessário caracterizar as perspectivas que os diversos usuários das informações geradas a partir da identificação, mensuração, classificação, registro, consolidação, auditoria e análise dos fatos contábeis, bem como se verificando as maneiras pelas quais a contabilidade ambiental pode influenciar a inserção da organização no contexto da responsabilidade social corporativa.

Para Melo, Salles e Van Bellen (2012) atualmente, quando o tema de desenvolvimento é tratado, é impossível dissociar tal discussão das preocupações com a sustentabilidade do meio ambiente e dos sistemas econômico e social. Essa conciliação entre os conceitos de desenvolvimento econômico e meio ambiente caracteriza-se como o desenvolvimento sustentável, que na visão da ONU pode ser definida como a capacidade de explorar os recursos no presente, sem comprometer as necessidades das gerações futuras.

Recentemente, o trabalho de Gray (2010) aborda que a sustentabilidade começa a ser inserida no quotidiano das organizações, e que a contabilidade não poderia ficar alheia a

R. Cont. Ufba, Salvador-Ba, v. 8, n. 3, p. 21 - 37, set-dez 2014 
esse movimento. Compartilhando dessa linha de pensamento, Hopwood et al (2010, p. 2) afirmam que considerando-se as interligações entre os campos econômico, social e ambiental, a contabilidade tradicional, focada somente nos aspectos econômicos da vida organizacional, também deve se preocupar com a sustentabilidade ambiental e social, em suas práticas e relatórios. Assim como, em determinados períodos históricos, a contabilidade social e a contabilidade ambiental tiveram seus momentos de destaque, atualmente é a sustentabilidade ambiental, e a suas inter-relações com as teorias da contabilidade, que necessitam de um framework, para que pesquisadores possam desenvolver adequadamente suas pesquisas (GRAY, 2010).

Verifica-se, pois, que a área denominada Contabilidade Ambiental, bem como as interfaces entre as áreas social e ambiental, que abarcam o conceito de sustentabilidade, podem e devem ser tratadas por profissionais e pesquisadores, uma vez que os reflexos das informações dessa natureza podem provocar alterações no processo de tomada de decisão de diversos atores da sociedade.

\subsection{Estudos bibliométricos realizados na área contábil}

O ineditismo do presente estudo caracteriza-se pela investigação específica sobre as produções científicas brasileiras relacionadas à contabilidade e sustentabilidade. Em estudo pioneiro, Nascimento et al (2009) identificaram e caracterizaram a pesquisa em Disclosure Social e Ambiental (DAS) em periódicos de língua inglesa, concluindo a partir de levantamento bibliométrico e análise de redes sociais que a temática mais estudada na área é a ambiental, cujos principais centros de estudos concentram-se no Reino Unido, Austrália, Estados Unidos, Canadá e Nova Zelândia.

Em um contexto mais amplo, os estudos bibliométricos abrangem diferentes linhas de investigação inseridas na área contábil. Cunha et al (2010) identificaram as abordagens metodológicas e técnicas de pesquisa utilizadas nos artigos científicos sobre contabilidade internacional publicados no Congresso de Controladoria e Contabilidade USP e Revista de Contabilidade \& Finanças USP, onde destaca-as, entre outras conclusões, uma predominância de análise bibliográfica como técnica de pesquisa em $65,7 \%$ dos artigos analisados.

No campo da contabilidade de custos e agronegócio, dois estudos avaliaram de modo bibliométrico as produções no maior evento da área, bem como no periódico mais destacável. Souza e Rasia (2011) traçaram um perfil sobre os artigos relativos ao tema custos do agronegócio, apresentados nas edições do Congresso Brasileiro de Custos (ABC), no período de 1998 a 2008. Já Walter (2010) traçou o mesmo perfil no periódico Custos e @gronegócio on line entre os anos de 2005 e 2010. Em ambos estudos observou-se uma caracterização de pesquisas voltadas aos custos de produção agroindustriais.

Nascimento et al (2010) traçaram um panorama longitudinal da produção científica em periódicos de contabilidade relacionada ao mercado de capitais, cuja amostra foi composta por 50 artigos científicos publicados em periódicos de contabilidade da área de Administração, Ciências Contábeis e Turismo, listados como A1, A2, B1, B2, B3, B4, B5 e C, segundo o sistema QUALIS-CAPES do triênio 2009/2011, com a pesquisa sendo relativa ao período de 1998 a 2008. Os autores concluíram quem o periódico com o maior número de publicações foi a Revista de Contabilidade e Finanças; o assunto mais recorrente faz menção às ações e que apenas 2 autores se destacaram como mais prolíficos (NASCIMENTO et al, 2010).

A partir dos estudos mencionados, além de outros que trataram da avaliação de perfis de produção científica nacional e internacional, observa-se que os estudos bibliométricos

R. Cont. Ufba, Salvador-Ba, v. 8, n. 3, p. 21 - 37, set-dez 2014 
ganham representatividade no cenário contábil brasileiro. As caracterizações e análises nas áreas de conhecimento da contabilidade compreendem uma necessidade a fim de suprir as lacunas de investigações científicas específicas. Não diferente, a análise bibliométrica da contabilidade e sustentabilidade se faz necessária e torna-se relevante ao processo da área.

\section{METODOLOGIA}

Em relação aos métodos de pesquisa utilizados, este trabalho se classifica, quanto aos objetivos, como uma pesquisa descritiva, pois visa identificar e analisar a produção científica escrita sobre contabilidade ambiental e sustentabilidade, sem realizar inferências. De acordo com Gil (2006), o principal objetivo da pesquisa descritiva é realizar a descrição das características de determinada população ou estabelecimento de relações entre variáveis.

Com relação aos procedimentos, considera-se a pesquisa como eminentemente bibliográfica. Gil (2006) considera que este tipo de procedimento tem como direcionamento a ideia de pautar seu desenvolvimento sobre material bibliográfico já elaborado, principalmente livros e artigos científicos. Quanto à abordagem do problema, é do tipo quali-quantitativo, pois foram utilizadas técnicas estatísticas (estatística descritiva) no tratamento dos dados (Richardson, 1999), e posteriormente as informações receberam tratamento qualitativo, mediante a construção de categorias descritivas, utilizando-se da base de conceitos oriunda da plataforma teórica de investigação, buscando-se sintetizar/agrupar os artigos, permitindo uma melhor compreensão do fenômeno sob investigação (MARTINS; THEOPHILO, 2007).

Como técnica metodológica, utilizou-se a bibliometria, que se constitui em uma metodologia que permite a avaliação de artigos científicos por intermédio de suas características semelhantes. Pode-se identificar, quantificar e analisar a produção técnica e científica sobre um determinado assunto, em uma determinada data, em relação à produção de autores e instituições, além de outros aspectos (KOBASHI; SANTOS, 2008; SAES, 2000 apud MOURA; DALLABONA; LAVARDA, 2010). Segundo Guedes e Borschiver (2007) a bibliometria quantifica descreve e prediz o processo de comunicação escrita.

Para a realização da seleção e identificação dos periódicos, objeto de análise bibliométrica, foram executados os seguintes passos: (i) seleção dos periódicos da base de dados da CAPES (www.periodicos.capes.gov.br) que continham em seu título a expressão "contabilidade", bem como periódicos que continham em seu escopo ou foco a temática contábil. Para fins dessa pesquisa, foram considerados os estratos A1, A2, B1 e B2, que correspondem a 35,97\% do total de periódicos constantes do QUALISCAPES. A escolha destes estratos ocorreu em virtude de serem considerados aqueles com maior fator de impacto, tendo como requisito mínimo ter mais de três anos de publicações e estar presente em pelo menos 1 indexador (SCOPUS, EBSCO, DOAJ, GALE, CLASE, HAPI, ICAP, BSS). Após a análise dos periódicos, foram contemplados pela análise um total de 10 revistas; (ii) realização de busca eletrônica em cada periódico por meio do título, do resumo e de análise das palavras-chave. As palavras utilizadas foram ambiental, sustentabilidade, ecológico, socioambiental, balanço social; e (iii) análise exploratória do conteúdo dos trabalhos para verificar se correspondia ao recorte deste trabalho. A lista de periódicos pesquisados encontra-se elencada no quadro 1 :

R. Cont. Ufba, Salvador-Ba, v. 8, n. 3, p. 21 - 37, set-dez 2014 


\begin{tabular}{|l|c|}
\hline \multicolumn{1}{|c|}{ Título do Periódico } & QUALIS \\
\hline BBR Brazilian Business Review & A2 \\
\hline Organizações e Sociedade & A2 \\
\hline Revista Contabilidade \& Finanças & A2 \\
\hline Contabilidade Vista \& Revista & B1 \\
\hline Revista de Contabilidade e Organizações & B1 \\
\hline Revista Universo Contábil & B1 \\
\hline Base (UNISINOS) & B1 \\
\hline Contabilidade, Gestão e Governança & B2 \\
\hline Custos e @ gronegócio Online & B2 \\
\hline Enfoque Reflexão contábil & B2 \\
\hline
\end{tabular}

Fonte: elaborado pelos autores

Quadro 1 - Lista dos periódicos analisados e estrato QUALIS

Posteriormente a seleção inicial dos artigos, foi criado um banco de dados para a categorização das informações coletadas e realização da análise bibliométrica. $\mathrm{O}$ banco de dados, organizado em planilha do Microsoft Excel (® contemplou o nome do periódico; título do artigo, ano de publicação; autores; instituições às quais estavam vinculados à época da publicação; palavras-chave e metodologia. Após análise detalhada, foram selecionados um total de 62 artigos. A análise dos resultados da pesquisa foi de caráter descritivo.

O período determinado para análise foi compreendido de 2007 a 2011. A seleção desse período ocorreu em virtude de que havia, na data de coleta de dados, periódicos que não haviam publicado todas as edições do ano de 2012, o que poderia prejudicar a comparabilidade dos dados dos periódicos. Outro fator que determinou a seleção do período em questão foi a crise financeira de 2008, cujos primeiros fatos foram divulgados a partir do segundo semestre. Considerando-se o prazo médio entre o envio, aprovação e publicação de artigos em periódicos (de 6 meses a 1 ano), considerou-se o período dividido da seguinte forma: dois anos antes da crise financeira (2007 e 2008), um ano no qual os reflexos da crise tiveram maior divulgação (2009) e dois anos após a crise financeira (2010 e 2011).

Para fins de análise dos artigos selecionados, buscou-se determinar um perfil dos mesmos, relacionando os seguintes itens: a) apresentação das revistas e a quantidade de artigos encontrados; b) período das publicações; c) verificação dos temais mais abordados nas pesquisas; d) evidenciação dos procedimentos metodológicos utilizados nos artigos; d) identificação da quantidade de autores por artigos e dos autores mais prolíficos; e) seleção das instituições de origem dos autores, com análise sobre a existência de redes de pesquisa na área ambiental.

Vale ressaltar, como limitação deste trabalho, o fato de não serem analisadas pesquisas em periódicos com QUALIS inferior a B2, assim como não foram objeto de verificação periódicos não constantes no sítio da CAPES na data da pesquisa, devido à delimitação da metodologia de busca e seleção dos periódicos.

\section{APRESENTAÇÃO E ANÁLISE DOS DADOS}

Considerando-se a importância das pesquisas sobre temas relativos à sustentabilidade, para a área contábil, visando cumprir os objetivos da pesquisa e de acordo com a metodologia descrita, apurou-se as informações sobre as publicações na área contábil, que versassem sobre o tema sustentabilidade ambiental.

R. Cont. Ufba, Salvador-Ba, v. 8, n. 3, p. 21 - 37, set-dez 2014 
A primeira análise realizada refere-se à verificação, junto aos periódicos pesquisados, do quantitativo de artigos que tratavam de temas relativos à sustentabilidade ambiental, no período. Os resultados estão apresentados na tabela 1:

Tabela 1: Proporção de artigos da área de sustentabilidade ambiental, em relação ao total de artigos pesquisados

\begin{tabular}{l|c|c|c}
\hline \multirow{2}{*}{\multicolumn{1}{c|}{ Título do Periódico }} & \multicolumn{2}{c|}{ Artigos pesquisados } & \multirow{2}{*}{} \\
\cline { 2 - 3 } & Totais & $\begin{array}{c}\text { Sustentabilidade } \\
\text { Ambiental }\end{array}$ & $\%$ \\
\hline BBR Brazilian Business Review & 93 & 2 & $2,15 \%$ \\
\hline Base (UNISINOS) & 121 & 3 & $2,48 \%$ \\
\hline Revista Contabilidade \& Finanças & 103 & 4 & $3,88 \%$ \\
\hline Organizações e Sociedade & 184 & 8 & $4,35 \%$ \\
\hline Contabilidade Vista \& Revista & 108 & 5 & $4,63 \%$ \\
\hline Custos e @ gronegócio Online & 110 & 6 & $5,45 \%$ \\
\hline Revista de Contabilidade e Organizações & 106 & 6 & $5,66 \%$ \\
\hline Revista Universo Contábil & 164 & 12 & $7,32 \%$ \\
\hline Contabilidade, Gestão e Governança & 91 & 7 & $7,69 \%$ \\
\hline Enfoque Reflexão contábil & 99 & 9 & $9,09 \%$ \\
\hline \multicolumn{1}{c}{ Totais } & 1179 & 62 & $5,26 \%$ \\
\hline Fonte: & & &
\end{tabular}

Fonte: elaboração dos autores

De um total de 1179 artigos pesquisados, 62 tratavam de temas relativos à área de sustentabilidade ambiental, ou seja, 5,26\%. O periódico com maior proporção de artigos publicados nessa área, no período analisado, foi a revista "Enfoque Reflexão Contábil", com 9,09\% do total de artigos, sendo que o periódico BBR Brazilian Business Review apresentou a menor proporção, com 2,15\%. A apuração de tais dados não representa um menor interesse sobre temas ligados à sustentabilidade pelos periódicos, mas representa um panorama entre os artigos enviados e aprovados pelos avaliadores e editores de tais periódicos.

A segunda análise realizada diz respeito ao número de artigos publicados por ano de publicação. Objetivou-se verificar a existência de alteração no interesse de pesquisadores e editores para outros assuntos, que não da área de sustentabilidade. Os resultados encontram-se demonstrados na tabela 2 :

\begin{tabular}{c|c|c} 
Tabela 2 - Distribuição dos artigos por ano de publicação \\
Ano & $\mathrm{n}^{\mathbf{0}}$ de artigos & $\%$ \\
\hline 2007 & 8 & 12,90 \\
\hline 2008 & 10 & 16,13 \\
\hline 2009 & 14 & 22,58 \\
\hline 2010 & 18 & 29,03 \\
\hline 2011 & 12 & 19,36 \\
\hline Total & $\mathbf{6 2}$ & $\mathbf{1 0 0}$
\end{tabular}

Fonte: elaborado pelos autores

De acordo com as informações apresentadas, verifica-se que, contrariamente aos estudos realizados por Pessan et al (2012) e por Rosa et al (2011), a produção acadêmica em periódicos nacionais referenciados pelo QUALIS-CAPES, na amostra pesquisada, apresentaram um crescimento no período, tendo seu ápice no ano de 2010, quando ocorreu a publicação de 18 artigos sobre temas relativos à área de R. Cont. Ufba, Salvador-Ba, v. 8, n. 3, p. 21 - 37, set-dez 2014 
sustentabilidade. Embora não haja comprovação estatística, a apreciação visual da Tabela 2 permite concluir que a crise financeira de 2008 não provocou um impacto negativo no número de artigos publicados, sendo que ocorreu uma redução apenas do ano de 2010 para o ano de 2011, de aproximadamente 33,33\%. Mesmo admitindo-se um período entre submissão e avaliação dos artigos de um ano, aproximadamente, a redução observada ocorreu dois anos após o evento, o que não permite mensurar os seus efeitos.

A próxima análise diz respeito aos temas específicos abordados nos artigos. Para a realização desse processo, foram examinadas todas as palavras-chave de todos os artigos selecionados. Cabe ressaltar que, durante a análise, dois artigos publicados não continham palavras-chave. O Quadro 2 apresenta os resultados da pesquisa de todas as palavras-chave que foram mencionadas em 2 ou mais artigos.

\begin{tabular}{|l|c|}
\hline \multicolumn{1}{|c|}{ Palavra-chave } & $\mathbf{n}^{\mathbf{0}}$ de ocorrências \\
\hline BOVESPA & 2 \\
\hline Unidades de Conservação & 2 \\
\hline Teoria Crítica & 2 \\
\hline Reconhecimento contábil & 2 \\
\hline MDL & 2 \\
\hline Ecoeficiência & 2 \\
\hline Disclosure Ambiental & 2 \\
\hline Demonstrações Contábeis & 2 \\
\hline Custos Ambientais & 2 \\
\hline Créditos de Carbono & 2 \\
\hline Teoria da Legitimidade & 3 \\
\hline ICMS Ecológico/Socioambiental & 3 \\
\hline Desenvolvimento Sustentável & 3 \\
\hline Desempenho Ambiental & 3 \\
\hline Balanço Social & 3 \\
\hline Informações ambientais/sociais & 4 \\
\hline Meio-Ambiente & 5 \\
\hline Sustentabilidade ambiental/empresarial & 6 \\
\hline Responsabilidade ambiental / social & 6 \\
\hline Gestão Ambiental & 6 \\
\hline Evidenciação/Evidenciação ambiental & 11 \\
\hline Contabilidade Ambiental & 11 \\
\hline
\end{tabular}

Quadro 2 - Ocorrência de palavras-chave nos artigos

Fonte: elaborado pelos autores

Como pode ser observado, os termos mais mencionados dizem respeito a Contabilidade Ambiental e Evidenciação/Evidenciação ambiental. Se considerarmos o termo "disclosure" como sinônimo de evidenciação, esse tema apresenta um total de 13 citações, suplantando a própria Contabilidade Ambiental. De forma complementar, verifica-se que os termos "Sustentabilidade", "Responsabilidade" e "Gestão", de natureza ambiental, social ou empresarial, foram encontrados em 6 artigos, o que representa um relevante interesse sobre essas áreas de pesquisa. Pode-se considerar que o tema Sustentabilidade Ambiental se constitui em um amplo aspecto de termos-chave utilizados pelos autores, que se consideram apresentados no quadro 2.

Por sua vez, temas específicos da área contábil, como "reconhecimento contábil", "demonstrações contábeis" e "custos ambientais" foram mencionados como termos chave em apenas 2 artigos. Esses temas, assim como outros, que foram pouco

R. Cont. Ufba, Salvador-Ba, v. 8, n. 3, p. 21 - 37, set-dez 2014 
explorados, representam oportunidades de pesquisa, uma vez que, de acordo com as informações apuradas, foram objeto de poucos estudos.

Quando verificada a quantidade de autores por artigo, pode-se observar a seguinte distribuição:

Tabela 3 - Número de autores por artigo

\begin{tabular}{l|c|c}
\multicolumn{1}{c|}{$\mathrm{N}^{\mathbf{o}}$ de autores } & Quantidade de artigos & $\%$ \\
\hline Um autor(a) & 7 & 11,30 \\
\hline Dois autores & 20 & 32,25 \\
\hline Três autores & 20 & 32,25 \\
\hline Quatro autores & 12 & 19,36 \\
\hline Cinco autores & 3 & 4,84 \\
\hline Total & 62 & 100
\end{tabular}

Fonte: elaborado pelos autores

A maior quantidade de artigos, ou seja, aproximadamente $64,5 \%$ do total, apresentaram dois ou três autores, sendo que 15 artigos apresentam um total de 4 autores ou mais. Apenas 7 artigos, ou $11 \%$ do total da amostra, foram elaborados por apenas um autor. Tais resultados contrastam com a pesquisa realizada por Nascimento et al (2009), que ao analisarem os artigos publicados sobre disclosure social e ambiental em periódicos internacionais, chegaram à conclusão que $75 \%$ dos artigos tinham um ou dois autores, sendo que apenas $25 \%$ do total apresentou três ou quatro autores.

Do total de 170 autores que publicaram em periódicos da área contábil, conforme descrito na seção destinada à metodologia de pesquisa, distribuídos nos 62 artigos, foram analisados aqueles que tinham mais de um artigo publicado, sendo os resultados demonstrados no quadro 3:

\begin{tabular}{|l|c|}
\hline \multicolumn{1}{|c|}{ Nome do autor } & Quantidade de artigos \\
\hline Aracéli Cristina de Souza Ferreira & 2 \\
\hline Ariovaldo dos Santos & 2 \\
\hline Cassio Luis Velane & 2 \\
\hline Gislane Ferreira Barbosa & 2 \\
\hline Hans Michael Van Bellen & 2 \\
\hline Marcia Reis Machado & 2 \\
\hline Marcio André Veras Machado & 2 \\
\hline Monica Cavalcante Sá de Abreu & 2 \\
\hline Silvania Neris Nossa & 2 \\
\hline Waldeci Rodrigues & 2 \\
\hline Fernando Dal Ri Murcia & 3 \\
\hline José Alonso Borba & 3 \\
\hline Laura Calixto & 3 \\
\hline Maisa de Souza Ribeiro & 3 \\
\hline Marivane Vestena Rossato & 3 \\
\hline Suliane Rover & 3 \\
\hline Valcemiro Nossa & 3 \\
\hline Vivian Osmari Uhlmann & 3 \\
\hline Elisete Dahmer Pfitscher & 5 \\
\hline For & \\
\hline
\end{tabular}

Fonte: elaborado pelos autores

Quadro 3 - Autores com mais de um artigo publicado

Os autores mais prolíficos estão demonstrados no Quadro 3. Para efeitos de análise, foram destacados a quantidade de trabalhos que eles publicaram no banco de dados elaborado para este trabalho. Pode ser dado um destaque para a autora Elisete Dahmer

R. Cont. Ufba, Salvador-Ba, v. 8, n. 3, p. 21 - 37, set-dez 2014 
Pfistscher, que apresentou um total de 5 artigos, sendo que 8 autores publicaram 3 artigos no período analisado. Outros 10 autores publicaram 2 artigos, sendo que a maioria absoluta dos autores (151 autores) realizou a publicação de apenas 1 artigo sobre o tema sustentabilidade ambiental nos periódicos pesquisados, do ano de 2007 a 2011.

Após a realização da análise por autores, optou-se por classificar os autores dos artigos pelas instituições de origem. Considerou-se, para essa finalidade, a instituição à qual o autor estava vinculado profissional e academicamente, quando disponível tal informação no artigo. No caso de haver duas instituições de origem relatadas, em virtude do autor ser aluno de pós-graduação de uma determinada instituição e estar vinculado à outra instituição, foi considerada apenas a instituição profissional, em virtude da característica do vínculo profissional ser, em tese, mais duradouro, que o vínculo acadêmico como discente, que tem sua natureza temporária.

Foram descritos, nos artigos selecionados, 35 instituições de ensino superior nacionais e 9 instituições de ensino superior internacionais. Das instituições de ensino nacionais, 23 instituições constaram como sendo origem de apenas 1 artigo. As instituições que figuraram em mais de 1 artigo estão representadas no quadro 4:

\begin{tabular}{|l|c|}
\hline \multicolumn{1}{|c|}{ Sigla da Instituição } & $\mathrm{N}^{\mathbf{o}}$ de artigos \\
\hline PUC SP & 2 \\
\hline UERJ & 2 \\
\hline UF TOCANTINS & 2 \\
\hline UFRGS & 2 \\
\hline UFC & 3 \\
\hline UFPB & 3 \\
\hline FUCAPE & 4 \\
\hline UFSM & 4 \\
\hline USP - RP & 4 \\
\hline UFRJ & 5 \\
\hline USP & 8 \\
\hline UFSC & 15 \\
\hline FO
\end{tabular}

Fonte: elaborado pelos autores

Quadro 4 - Instituição de origem dos autores

O destaque, nesse quadro, é a Universidade Federal de Santa Catarina (UFSC), que foi mencionada como instituição de origem pelos autores de 15 artigos. A existência de um núcleo de pesquisadores na área de estudos da sustentabilidade ambiental, nessa instituição, apresentou-se como tendo forte impacto em periódicos qualificados na área de Administração, Ciências Contábeis e Turismo. Como complemento, destaca-se que a autora com maior número de publicações, Elisete Dahmer Pfitscher, encontra-se atualmente vinculada à UFSC.

Outras duas instituições que merecem destaque são a Universidade de São Paulo (USP), com 8 artigos publicados, e a Universidade Federal do Rio de Janeiro (UFRJ), com cinco artigos publicados, no período analisado.

Por fim, com base nos levantamentos desenvolvidos, foi realizada a caracterização metodológica dos artigos investigados, subdividida quanto ao método, estratégia, técnica e tipo de pesquisa (RICHARDSON, 1999; DEMO, 2011; FLICK, 2009; GIL, 2006; MARCONI E LAKATOS, 2004; SEVERINO, 2007). A Tabela 4 sintetiza os resultados encontrados a partir da utilização da técnica bibliométrica de pesquisa.

Tabela 4: Caracterização metodológica dos artigos pesquisados

R. Cont. Ufba, Salvador-Ba, v. 8, n. 3, p. 21 - 37, set-dez 2014 


\begin{tabular}{|c|c|c|c|c|c|}
\hline Característica & Classificação & Quantidade & Total & Percentual & Total $(\%)$ \\
\hline \multirow{4}{*}{ Método de pesquisa } & Ensaio teórico & 07 & \multirow[b]{4}{*}{62} & $11,29 \%$ & \multirow[b]{4}{*}{$100 \%$} \\
\hline & Quantitativo & 16 & & $25,81 \%$ & \\
\hline & Qualitativo & 34 & & $54,84 \%$ & \\
\hline & Quali-quanti & 05 & & $8,06 \%$ & \\
\hline \multirow{7}{*}{ Estratégia de pesquisa } & Bibliográfico & 14 & \multirow[b]{7}{*}{62} & $22,59 \%$ & \multirow[b]{7}{*}{$100 \%$} \\
\hline & Documental & 23 & & $37,1 \%$ & \\
\hline & Experimental & 01 & & $1,61 \%$ & \\
\hline & Pesquisa-ação & 00 & & 0 & \\
\hline & Estudo de Caso & 19 & & $30,65 \%$ & \\
\hline & Pesquisa participante & 00 & & 0 & \\
\hline & Não identificada & 05 & & $8,05 \%$ & \\
\hline \multirow{5}{*}{ Técnica de pesquisa } & Análise documental & 22 & \multirow[b]{5}{*}{62} & $35,48 \%$ & \multirow[b]{5}{*}{$100 \%$} \\
\hline & Entrevista/questionário & 17 & & $27,42 \%$ & \\
\hline & Observação & 00 & & 0 & \\
\hline & Análise de conteúdo & 13 & & $20,97 \%$ & \\
\hline & Múltiplas & 10 & & $16,13 \%$ & \\
\hline \multirow{5}{*}{ Tipo de pesquisa } & Exploratório & 24 & \multirow[b]{5}{*}{62} & $38,72 \%$ & \multirow[b]{5}{*}{$100 \%$} \\
\hline & Descritivo & 25 & & $40,32 \%$ & \\
\hline & Explicativo & 05 & & $8,06 \%$ & \\
\hline & Observação & 01 & & $1,61 \%$ & \\
\hline & Empírico-analítico & 07 & & $11,29 \%$ & \\
\hline
\end{tabular}

Fonte: elaborado pelos autores

$\mathrm{Na}$ caracterização do método de pesquisa utilizado nos artigos, observou-se a predominância dos estudos qualitativos em $54,84 \%$ das produções, seguido por $25,81 \%$ de estudos quantitativos, $11,29 \%$ de ensaios teóricos e $8,06 \%$ de método quali-quanti. Para Richardson (1999) os estudos que empregam uma abordagem qualitativa podem descrever a complexidade de determinado problema, analisar a interação de certas variáveis, compreender e classificar processos dinâmicos vividos por grupos sociais. Neste sentido, a mensuração ou quantificação dos dados relativos à sustentabilidade na área contábil, a partir dos artigos verificados, perde relevância à interpretação dos mesmos para a formação de conceitos e informações almejadas.

Quanto à estratégia de pesquisa utilizada, as principais classificações encontradas foram os estudos documentais $(37,1 \%)$, os estudos de caso $(30,65 \%)$ e os estudos bibliográficos $(22,59 \%)$. Nos estudos documentais verificou-se a predominância da utilização de documentos divulgados pelas empresas relacionados à evidenciação de aspectos ambientais, bem como práticas de contabilidade ambiental.

Já em relação às técnicas de pesquisa contempladas nos artigos, as análises documentais foram utilizadas em 35,48\% dos estudos, seguida de entrevista/questionário $(27,42 \%)$, análise de conteúdo $(20,97 \%)$ e múltiplas classificações $(16,13 \%)$. Tomando como base que a maioria das práticas de sustentabilidade ambiental e contabilidade ambiental são publicadas pelas próprias empresas em documentos diversificados, tal predominância classificatória (análise documental) é explicada.

Como finalização do estudo bibliométrico, observou-se a classificação metodológica dos artigos quanto ao tipo de pesquisa. De modo específico, a predominância recaiu sobre investigações descritivas $(40,32 \%)$ e exploratórias $(38,72 \%)$, refletindo sobre a pouca influência de investigações explicativas em estudos relacionados à áreas contábil $(8,06 \%)$. A maioria dos artigos contempla a descrição de dados levantados sobre determinada situação (GIL, 2006) ou exploram/levantam informações sobre um objetivo específico (SEVERINO, 2002). 


\section{CONCLUSÕES}

O presente estudo se propôs a responder o seguinte problema de pesquisa: qual o perfil das publicações sobre a temática da sustentabilidade ambiental, em periódicos científicos referenciados pelo QUALIS-CAPES de Ciências Contábeis, no período de 2007 a 2011? Como resposta inicial ao questionamento, pôde-se concluir a baixa produtividade em relação à temática, sendo que em apenas 5,26\% dos artigos pesquisados junto aos periódicos da área contábil, referenciadas pelo QUALIS-CAPES no período de 2007 a 2011. Dos 62 artigos mencionados, os temas específicos predominantes foram a evidenciação/evidenciação ambiental e contabilidade ambiental. Já em relação ao objetivo secundário relacionado a analisar as influências da crise financeira mundial de 2008 nos temas das produções da área contábil, pôde-se verificar que não houve impacto negativo nas publicações relacionadas à sustentabilidade, tendo em vista o ano de 2010 ter sido o de maior predominância de investigações.

$\mathrm{Na}$ classificação bibliométrica realizada, constatou-se que $54,84 \%$ dos artigos analisados contemplavam o método qualitativo de abordagem do problema, constatando-se a oportunidade para realização de pesquisas quantitativas, com comprovações estatísticas em relação às possíveis variáveis levantadas, em estudos cuja temática contemple práticas de sustentabilidade e contabilidade ambiental.

Quanto às estratégias das 62 pesquisas, verificou-se que em $37,1 \%$ dos casos foi utilizada a documental e, consequentemente como técnica, em 35,48\% dos casos foi identificada a análise documental. Tal fator demonstra a real necessidade de mais produções bibliográficas relacionadas aos temas ligados à área de sustentabilidade ambiental, na área contábil, principais investigados, tendo em vista que a maior parte dos estudos baseia-se apenas em documentos emitidos tanto por empresas privadas, quanto por entidades públicas, devendo-se levar em consideração a dificuldade de realização de pesquisas empíricas em empresas, no Brasil.

Por fim, respectivamente 40,32\% e $38,72 \%$ dos artigos investigados apresentaram tipologias de pesquisa descritiva e exploratória, demonstrando assim que em apenas 11,29\% dos casos aplicou-se a classificação empírica-analítica. Essa última pode refletir a real necessidade de utilização, tendo em vista a relevância dos estudos empíricos quando se trata da área de sustentabilidade ambiental no Brasil, recomendando-se aos pesquisadores a prudência na coleta e análise de dados, tendo em vista a possível tendência de divulgar apenas informações positivas, relativas a essa temática abrangente, que é a sustentabilidade ambiental.

\section{REFERÊNCIAS}

BALLOU, Brian, CASEY, Ryan J., GRENIER, Jonathan H., and Dan L. Heitger (2012) Exploring the Strategic Integration of Sustainability Initiatives: Opportunities for Accounting Research. Accounting Horizons: June 2012, Vol. 26, No. 2, pp. 265-288. doi: http://dx.doi.org/10.2308/acch-50088

BARBOSA, Vanessa. Nem o meio ambiente escapa da crise na zona do euro. Exame.com, em 18/11/2011. Disponível em http://exame.abril.com.br/. Acesso em 21/01/2013.

CALlADO, Antônio. A. C; CALLADO, Aldo L. C. Índices Financeiros Ambientais: Uma Proposta Conceitual. In: ENGEMA - ENCONTRO NACIONAL SOBRE

R. Cont. Ufba, Salvador-Ba, v. 8, n. 3, p. 21 - 37, set-dez 2014 
GESTÃO EMPRESARIAL E MEIO AMBIENTE, 9. Anais... CURITIBA, 19 a 21 de novembro de 2007. Disponível em:

http://engema.up.edu.br/arquivos/engema/pdf/PAP0085.pdf . Acesso em 30/01/2013.

CAMPOS, Gabriel M. O impacto de indicadores socioambientais no valor adicionado por empresas. Enfoque - Reflexão Contábil. v. 30 n. 1 p. 83-93. 2011.

CUNHA, Paulo Roberto da; RAUSCH, Rita Buzzi; CUNHA, Jacqueline Veneroso Alves da. Contabilidade internacional: uma análise metodológica e técnica das pesquisas publicadas no Congresso USP de Controladoria e Contabilidade e na Revista de Contabilidade \& Finanças da USP. Contabilidade, Gestão e Governança. Brasília, v.13, n.3, p.116-131, Set/Dez 2010.

DEMO, Pedro. Praticar ciência: metodologias do conhecimento científico. São Paulo: Saraiva, 2011.

DOWBOR, Ladislau. Planeta Sustentável. 18/12/2008. Disponível em http://planetasustentavel.abril.com.br/ . Acesso em 20/01/2013

FLICK, Uwe. Qualidade na pesquisa qualitativa. Porto Alegre: Bookman, 2009.

FRIEDMAN, M. The social responsibility of business is to increase its profits. The New York Times Magazine, Sep., 1970.

GIL, Antonio Carlos. Como elaborar projetos de pesquisa. 4. ed. São Paulo: Atlas, 2006.

GRAY, Rob. Is accounting for sustainability actually accounting for sustainability... and how would we know? An exploration of narratives of organisations and the planet.

Accounting, Organizations and Society. Volume 35, Issue 1, January 2010, Pages 4762

GRI - Global Reporting Initiative: Disponível em: www.globalreporting.org (Acesso em 10/01/2013).

GUEDES, V. L.; BORSCHIVER, S. Bibliometria: uma ferramenta estatística para a gestão da informação e do conhecimento, em sistemas de informação, de comunicação e de avaliação científica e tecnológica. Disponível em: <http: //www.cinform.ufba.br/vi_anais/docs/VaniaLSGuedes.pdf >. Acesso em: 19/01/2013.

HOPWOOD, Anthony, UNERMAN, Jeffrey, FRIES, Jessica. Introduction to the Accounting for Sustainability Case Studies. In Accounting for Sustainability: Pratical Insights. London, UK., 2010

KRAEMER, Maria . E. P. Contabilidade ambiental: relatório para um futuro sustentável, responsável e transparente. Disponível em:

http://www.universoambiental.com.br/Contabilidade/Contabilidade_FuturoSust.htm

Acesso em 30/01/2013.

R. Cont. Ufba, Salvador-Ba, v. 8, n. 3, p. 21 - 37, set-dez 2014 
MARCONI, Maria de Andrade; LAKATOS, Eva Maria. Metodologia científica. 4. ed. São Paulo: Atlas, 2004.

MARTINS, Gilberto de A., THEÓPHILO, Carlos R. Metodologia da investigação científica para ciências sociais aplicadas. São Paulo: Atlas, 2007.

MATHEWS, M.R. Twenty-fi ve years of social and environmental accounting research. Is there a silver jubilee to celebrate? Accounting, Auditing \& Accountability Journal. v. 10 n. 4, p. 481-531. 1997.

MELO, Paulo T. N. B. de, SALLES, Helena K. de., Van Bellen, Hans M. Quadro institucional para o desenvolvimento sustentável: o papel dos países em desenvolvimento com base na análise crítica do discurso da Rio+20. Cadernos EBAPE.BR. Vol.10 no.3 Rio de Janeiro Sept. 2012.

MENDONÇA NETO, Octávio R. de. RICCIO, Edson L., CARDOSO, Ricardo L., SAKATA, Marici C. G. A Contabilidade como instrumento de exercício de poder: a visão de Lênin em "O Estado e a Revolução". RIC - Revista de Informação Contábil - Vol. 4, no 3, p. 1-17, Jul-Set/2010.

MOURA, Geovanne Dias de; DALLABONA, Lara Fabiana; LAVARDA, Carlos Eduardo Facin. Estudo bibliométrico sobre orçamento nos congressos brasileiros de 2005 a 2009. In: CONGRESSO ANPCONT, 4., 2010, Natal. Anais... Natal: ANPCONT, 2010. CD-ROM.

NASCIMENTO, Artur R. do., SANTOS, Ariovaldo dos., SALOTTI, Bruno., Murcia, Fernando Dal-Ri. Disclosure Social e Ambiental: Análise das Pesquisas Científicas Veiculadas em Periódicos de Língua Inglesa. Contabilidade Vista \& Revista. Belo Horizonte, v. 20, n. 1, p. 15-40, jan./mar. 2009.

NASCIMENTO, Sabrina do; PEREIRA, Alexandre M; TOLEDO FILHO, Jorge R. de. Produção científica em periódicos de contabilidade relacionada ao mercado de capitais. Contabilidade, Gestão e Governança. Brasília, v.13, n.1, p.32-43, Jan/Abr 2010.

PESSAN, Maria A. B., PINHEIRO, Cleberson J., REIS, Luciano G., TARIFA, Marcelo R., NOGUEIRA, Daniel R. PRODUÇÃO CIENTÍFICA EM CONTABILIDADE AMBIENTAL: Uma análise histórica do Congresso USP de Controladoria e Contabilidade. Educação Ambiental em Ação. N. 41, Ano XI. SetembroNovembro/2012.

PFISTCHER, Elisete Dahmer. Gestão e sustentabilidade através da contabilidade e contabilidade ambiental: estudo de caso na cadeia produtiva de arroz ecológico. 2004. 252 f. Tese (Doutorado em Engenharia de Produção) - Curso de Pós-graduação em Engenharia de Produção, Universidade Federal de Santa Catarina. Florianópolis. 2004.

REIS, Luciano. G.; NOGUEIRA, Daniel R.; TARIFA, Marcelo R. Uma Análise Histórica das Publicações Existentes sobre o Tema Contabilidade Ambiental. Revista de Estudos Contábeis. Londrina, V. 2, N. 3, p.90-97, Jul./Dez. 2011 
RIBEIRO, Alex M., VAN BELLEN, Hans M., CARVALHO, Luiz N. G. de. Regulamentar faz diferença? O caso da evidenciação ambiental. Revista Contabilidade e Finanças - USP. v. 22, n. 56, p. 137-154, maio/jun./jul./ago. 2011

RICHARDSON, Roberto Jarry. Pesquisa social: métodos e técnicas. 3. ed. São Paulo: Atlas, 1999

ROSA, F. S. da; LUNKES, R. J.; FELIU, V. M. R.; ENSSLIN, S. R. Contabilidade Ambiental na Espanha: Análise de Referencial Teórico. In: XIII Congresso de Contabilidade e Auditoria. Porto: ACIM, 2011

RODRIGUES, Jorge J. M, DUARTE, Maria M.R.F.R. Relato da Responsabilidade Social, ambiente e competitividade: enquadramento teórico. Revista Universo Contábil, Blumenau, v. 7, n. 4, p. 138-155, out./dez., 2011.

SANTOS, Ariovaldo. Demonstração do valor adicionado: como elaborar e analisar a DVA. 2. ed. São Paulo: Atlas, 2007.

SEVERINO, Antônio Joaquim. Metodologia do trabalho científico. 23. ed. São Paulo: Cortez, 2007.

SOUZA, Marcos Antonio; RASIA, Kátia Arpino. Custos no agronegócio: um perfil dos artigos publicados nos Anais do Congresso Brasileiro de Custos no período de 1998 a 2008. Contabilidade, Gestão e Governança. Brasília, v.14, n.1, p.69-81, Jan/Abr 2011.

TINOCO, João. E. P.; KRAEMER, Maria E. P. Contabilidade e gestão ambiental. 2.ed. São Paulo: Atlas, 2008.

WALTER, Fábio. O perfil dos artigos publicados no Custos e @ gronegócio on line. Custos e @gronegócio on line. V.6, n.3, Set/Dez 2010. 